\title{
FOREWORD: COMPUTING IN SPACE AND ASTROPHYSICAL PLASMAS
}

This special issue of Space Science Reviews contains a collection of papers based on the invited talks presented at the WISER Workshop on Computing in Space and Astrophysical Plasmas (HPC2005) held from April 18 to 22, 2005 in Leuven, Belgium. This workshop was hosted by the Centre for Plasma Astrophysics of the Department of Mathematics of the Katholieke Universiteit Leuven. The venue of this workshop was the beautiful Arenberg Castle. The conveners of this international workshop were Marcel Goossens, Stefaan Poedts, and Yuriy Voitenko of the Katholieke Universiteit Leuven, and Abraham C.-L Chian of the National Institute for Space Research, Brazil. The local organizing committee was composed by Jesse Andries, Inigo Arregui, Anik De Groof, Marcel Goossens, Stefaan Poedts, Leona Vandezande, and Yuriy Voitenko of the Katholieke Universiteit Leuven.

The World Institute for Space Environment Research-WISER (http:// www.cea.inpe.br/wiser) is an international network of centers of excellence dedicated to promote collaboration in research and training on earth-ocean-space environment and on the study of the impact of space climate/weather on the earth's climate/weather, environment and technology, with emphasis on theory, computer modeling, and data/image analysis. The aim of the series of HPC workshops is to bring together space plasma physicists, plasma astrophysicists, applied mathematicians, and computational scientists interested in computing, theory, and observation in space and astrophysical plasmas. The first HPC 2002 workshop was hosted by the University of Adelaide, Australia. The proceedings of HPC 2002 was published as a special issue of Space Science Reviews by Chian and the WISER Team (2003) as well as a hardcover book entitled Advances in Space Environment Research Volume 1 by Chian and the WISER Team (2003).

Forty-two participants representing over 20 countries were invited to attend the HPC 2005 workshop. Thirty-five invited talks were presented. The scientific program of this workshop was divided into four sessions. Session I on plasma flows, shocks, and turbulence; session II on plasma physics of solar atmosphere; session III on physics of near-Earth plasmas; session IV on basic processes in astrophysical and space plasmas.

\section{References}

Chian, A. C-L. and WISER Team (eds.): 2003, Space Sci. Rev. 107 (1-2), 1-540.

Chian, A. C.-L. and WISER Team (eds.): 2003, Advances in Space Environment Research, Vol. 1 Kluwer, Dordrecht. 
Marcel Goossens, Stefaan Poedts and Yuriy Voitenko

Centre for Plasma Astrophysics

Katholieke Universiteit Leuven

Celestijnenlaan 200 B

3001 Leuven

Belgium

Abraham C.-L. Chian

National Institute for Space Research (INPE) and

World Institute for Space Environment Research (WISER)

P.O. Box 515

Sao Jose dos Campos-SP 12227-010, Brazil 